\title{
Assessing the Drivers of Short- and Long-Term Outcomes at Business Trade Shows
}

\author{
Shrihari Sridhar • Clay M. Voorhees • \\ Srinath Gopalakrishna
}

Published online: 24 February 2015

(C) Springer Science+Business Media New York 2015

\begin{abstract}
The trade show industry attracts millions of attendees every year, offering enormous opportunities for buyer-seller interactions and potential revenues for exhibitors. Business-to-business firms invest more than $20 \%$ of their marketing budgets on trade shows, with a heavy emphasis on pre- and at-show marketing efforts to generate booth traffic, as well as post-show marketing efforts to close sales leads. However, a comprehensive overview of the impact and effectiveness of trade show marketing efforts on lead generation and sales conversion is missing. Extant models consider only single stages of the buying process and fail to account for heterogeneous marketing effectiveness across customers. This study therefore addresses the incremental effects of pre-, at-, and post-show marketing efforts on short- and long-term outcomes, with customer type as a potential moderator of marketing effectiveness. Attendee-level data from multiple shows attended by a Fortune 500 corporation provide initial empirical evidence of the joint effects of marketing activities during the three different phases. By documenting the impact of various marketing activities across purchase stages and customer types, this study can help managers assess the effectiveness of their trade show marketing activities.
\end{abstract}

\footnotetext{
S. Sridhar $(\bowtie)$

Smeal College of Business, The Pennsylvania State University, 457

Business Building, University Park, PA 16802, USA

e-mail: sus55@psu.edu

C. M. Voorhees

Eli Broad College of Business, Michigan State University, N304

Business College Complex, East Lansing, MI 48824, USA

e-mail: voorhees@broad.msu.edu

S. Gopalakrishna

Robert J. Trulaske, Sr. College of Business, University of Missouri,

434 Cornell Hall, Columbia, MO 65211, USA

e-mail: srinath@missouri.edu
}

Keywords Trade shows $\cdot$ Sales response models $\cdot$ Marketing mix models $\cdot$ Resource allocation $\cdot$ Marketing strategy . Business-to-business

\section{Introduction}

Valued at more than $\$ 11$ billion, the trade show industry attracts approximately 1.5 million exhibitors and 60 million attendees every year (CEIR 2008 ${ }^{1}$ ). Considering the enormous opportunities they offer for buyer-seller interactions, trade shows constitute an integral part of the business-tobusiness (B2B) marketing mix, representing an average of $20 \%$ of total marketing budgets, ahead of both print advertising and direct mail [24]. However, the proliferation of Internet-enabled media also makes it easier for firms to reach and engage customers in cost-effective ways. Thus, marketing managers face mandates to demonstrate that their trade show investments deliver, for both the selling and nonselling objectives of the firm. Unfortunately, measurements of the impact of trade show marketing efforts on lead generation and sales are rare, and related research is limited. Dekimpe et al. ([5], p. 63) thus express the need to "assess the returns of various types of trade show investments in terms of lead generation, dollar contribution, and other exhibitor objectives," and on the practitioner side, Federbush ([6], p. 2) worries that "managers need better and more predictive information to help make key strategic and tactical decisions about event marketing programs."

The challenge in determining an exhibitor's marketing mix effectiveness relates to the availability of data that can track the entire sales process. To put this issue in perspective, we

\footnotetext{
${ }^{1}$ http://www.ceir.org/articles/detail/2008/CEIR-Releases-Fifth-AnnualIndex. Accessed Feb 10, 2015.
} 
briefly describe the nature of a typical exhibitor's marketing mix. Trade shows involve a combination of advertising and personal selling efforts. Pre-show and at-show marketing efforts (e.g., booth space, giveaways, and promotions) generate booth traffic, build awareness, and create forward progress in the purchasing process [8]. Exhibitors also invest in booth staffing and training to generate and assess visitors' product interest. After the trade show, exhibitors attempt to close their sales leads through promotion messages or sales calls to prospective buyers. Ideally, data would track attendees from their initial visit to the booth, all the way through to a purchase or otherwise, noting the firm's marketing efforts during the preshow, at-show, and post-show phases. Even if such data were available, a second challenge arises in attempting to build a response model that can demonstrate the relative impact of pre-, at-, and post-show activities on short- and long-term outcomes. Such a model needs to capture effects during both purchase intention formation and the purchase decision stages to reveal the relative effectiveness of marketing variables that are relevant in each stage of the selling process.

Extant research offers only a limited view of such a response model. Gopalakrishna and Lilien [8] focus on shortterm outcomes and show that pre- and at-show marketing efforts increase lead generation. Gopalakrishna et al. [9] also illustrate that exhibiting at a trade show results in more actual purchases after the show. However, each study focuses on a single or partial stage of the sales process. Focusing on shortterm outcomes ignores the sales dimension of exhibiting, whereas considering only the long-term effects risks overstating the impact of marketing efforts because it ignores outcomes such as purchase intentions that can form at the show. Extant models also exclude heterogeneity in marketing effectiveness, even though buyers differ in their responsiveness to marketing efforts.

To address these issues, we propose a model that incorporates pre-, at-, and post-show marketing efforts, as well as tangible at- and post-show outcomes. We develop hypotheses about marketing effectiveness in each phase, with customer status (i.e., prospect versus existing customer) acting as a moderator. Our analysis is based on data involving 2299 attendees at 10 shows at which a large, multinational, B2B information technology corporation in the USA exhibited its products. The data report the purchase intentions of these attendees toward the exhibiting company's products (obtained from an independent market research firm that also assessed satisfaction with other exhibitors). In addition, we include the focal firm's pre-, at-, and post-show marketing efforts and record whether each attendee bought a product exhibited at the trade show within 120 days of the show. The results indicate a statistically significant impact of pre-, at-, and postshow marketing efforts, which is important evidence for exhibitors seeking to allocate their resources across the trade show marketing mix. We also find evidence of heterogeneity in marketing effectiveness by customer type. We suggest, ways in which exhibitors could fine tune their resource allocation, on the basis of these contingencies.

From a theory perspective, our research advances current understanding of trade show effectiveness in several ways. First, we incorporate data that better reflect the multistage buying process. Our triadic (attendees, exhibitors, and show organizers) and longitudinal (before and after show) data collection exercise avoids single source bias and provides a robust test of our hypotheses. Second, we include short-term purchase intentions together with long-term objective sales conversion information. Third, we offer a contingent view of marketing effectiveness by including a relevant moderating variable.

In the next section, we review literature on trade show effectiveness, which demonstrates the need for a comprehensive trade show response model. We then develop hypotheses about the moderating role of customer type on trade show marketing efforts. Next, we describe the empirical setting, data, and measures and outline our model, linking pre-show, at-show, and post-show marketing efforts with multiple outcomes. We follow that description with a discussion of the results before concluding with a summary of the key takeaways.

\section{Conceptual Background}

Trade shows are an important component of the marketing mix for B2B firms, considering their ability to influence customer perceptions and purchase behaviors directly. Trade shows enable multiple interactions between buyers and sellers, and marketing efforts at these events typically involve more than a mere demonstration of the product. Exhibitors often actively manage several tactical marketing investments, including pre-show promotions, the at-show service experience, and post-show follow-up efforts. Pre-show activities include impersonal promotions, invitations to visit the booth, and mass mailings [8]. At-show investments include staffing decisions, such as staff density and booth-specific training $[15,17]$. Finally, the post-show follow-up involves direct contacts by sales representatives to close the sales leads generated at the show [23].

Thus, marketing investments span the entire sales process, in support of the exhibitor's goal of strategically influencing customers and prospects as they progress toward final purchase. Exhibiting firms typically have both selling and nonselling objectives, such as enhancing perceptions of the firm's products or promoting the image of the organization in the short term (at-show). The selling objectives focus on leveraging the credibility and goodwill developed at the show to convert leads into sales in the long term (post-show) [13]. 
However, the limited scope of prior research leaves some gaps in our understanding of how buyers evaluate their trade show experiences or how the experiences translate into purchases (see Table 1). For example, Gopalakrishna and Lilien [8] reveal the effects of tactical investments on the generation of sales leads, but they do not assess the impact of at-booth experiences on customer perceptions or the conversion of leads into sales. Ling-yee [17] and Lee and Kim [15] examine subjective outcomes following the trade show, but they do not consider any intermediate outcomes associated with the multiple phases of the trade show experience. They also rely on self-reported data from exhibitors. Collectively, past research does not capture the full impact of trade show investments on buyer intentions or behaviors.

To extend this research stream, we model the effects of marketing investments throughout the sales process on both short- and long-term outcomes, and we include customer type as a key contingency, influencing the relative effectiveness of marketing investments. We depict our proposed model in Fig. 1.

\section{Hypothesis Development}

\subsection{Effects of Pre-show Promotional Investments}

Exhibitors invest in pre-show promotions to generate awareness among buyers and encourage booth visits [15]. Such investments generally have positive effects on the attainment of trade show objectives [17]. Pre-show promotions serve as quality signals for the firm, as described by information integration theory $[1,2]$, such that when buyers receive new information through promotions, they integrate that information with other environmental cues to form updated attitudes and intentions. In the context of trade shows, pre-show promotions likely affect future evaluations (e.g., purchase intentions) because buyers will use both these sources of information to develop an overall impression of the firm. Thus, we propose:

$\mathrm{H}_{1 \mathrm{a}}$ : Pre-show promotions have a direct, positive effect on customers' purchase intentions.

Relational ties between sellers and buyers can have an effect on expectations of service, so the effectiveness of marketing actions also should vary across established versus prospective customers [20, 21]. For example, Rust and Verhoef [21] demonstrate that relationship-oriented investments are most effective with established customers. Extending this argument to trade show marketing investments, we posit that a firm's current customers may respond differently to pre-show promotions than prospects do. Given an existing relationship with current customers, the exhibiting firm benefits from their product awareness, so its pre-show promotions can reinforce positive prior experiences. In this case, promotions might be more effective with current customers [12]. Differentially positive effects of promotion then could result in a halo effect, such that positive evaluations of pre-show promotions have an impact on subsequent evaluations of service. Thus, we propose:

$\mathrm{H}_{1 b}$ : Pre-show promotions have a stronger effect on current customers' purchase intentions than on prospective customers.

\subsection{Effects of At-Show Selling Investments}

Once customers have been attracted to visit the booth, interactions with sales staff become relevant for converting

Table 1 Review of empirical research on trade show purchasing and performance

\begin{tabular}{|c|c|c|c|c|c|c|c|c|}
\hline \multirow[t]{2}{*}{ Article } & \multirow{2}{*}{$\begin{array}{l}\text { Model entire } \\
\text { purchase process }\end{array}$} & \multirow{2}{*}{$\begin{array}{l}\text { Include } \\
\text { contingency } \\
\text { effects }\end{array}$} & \multicolumn{4}{|c|}{ Dependent variables } & \multirow{2}{*}{$\begin{array}{l}\text { Multisource } \\
\text { data }\end{array}$} & \multirow{2}{*}{$\begin{array}{l}\text { Data from } \\
\text { multiple } \\
\text { shows }\end{array}$} \\
\hline & & & $\begin{array}{l}\text { Cross-sectional } \\
\text { DVs }\end{array}$ & $\begin{array}{l}\text { Longitudinal } \\
\text { DVs }\end{array}$ & $\begin{array}{l}\text { Perceptual } \\
\text { DVs }\end{array}$ & $\begin{array}{l}\text { Objective } \\
\text { DVs }\end{array}$ & & \\
\hline Current article & $\checkmark$ & $\checkmark$ & $\checkmark$ & $\checkmark$ & $\checkmark$ & $\checkmark$ & $\checkmark$ & $\checkmark$ \\
\hline Gopalakrishna et al. [10] & & & $\checkmark$ & & $\checkmark$ & & & \\
\hline Lee and Kim [15] & & & $\checkmark$ & & $\checkmark$ & & & \\
\hline Ling-yee [17] & & $\checkmark$ & $\checkmark$ & & $\checkmark$ & & & \\
\hline Smith et al. [23] & & & $\checkmark$ & $\checkmark$ & & $\checkmark$ & $\checkmark$ & \\
\hline Dekimpe et al. [5] & & $\checkmark$ & $\checkmark$ & & $\checkmark$ & $\checkmark$ & & $\checkmark$ \\
\hline Gopalakrishna et al. [9] & $\checkmark$ & & $\checkmark$ & $\checkmark$ & & $\checkmark$ & $\checkmark$ & \\
\hline Gopalakrishna and Lilien [8] & & & $\checkmark$ & & $\checkmark$ & $\checkmark$ & $\checkmark$ & \\
\hline Bello [3] & & & $\checkmark$ & & $\checkmark$ & & & \\
\hline Gopalakrishna and Williams [11] & & & $\checkmark$ & & & $\checkmark$ & & $\checkmark$ \\
\hline Kerin and Cron [13] & & & $\checkmark$ & & $\checkmark$ & & & \\
\hline
\end{tabular}




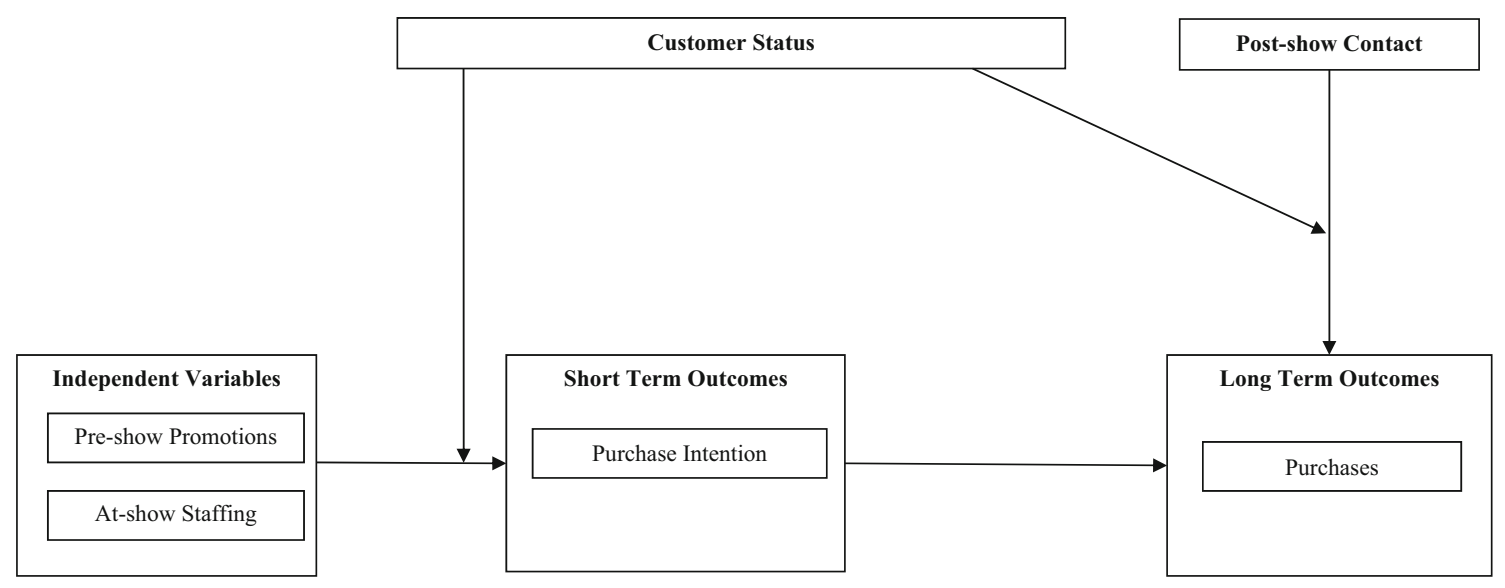

Fig. 1 Model of the drivers of short-term and long-term performance

prospects into qualified sales leads. For this conversion to occur, an adequate number of sales representatives must be available to interact with customers [11]. When more booth personnel are available, there is more time to inquire into and address buyer needs, which improves the quality of the attendees' experience [19]. The easiest way to facilitate booth interactions with customers and prospects is to manage booth staff availability appropriately. Prior research shows that more booth staff improves the overall impact of the selling effort [8]. Thus,

$\mathrm{H}_{2 \mathrm{a}}$ : The number of booth personnel has a direct, positive effect on customers' purchase intentions.

Prior research also shows that, aside from direct marketing efforts, customers' expectations change as they progress in a relationship with a supplier. Specifically, when customers stay longer in a relationship, the expertise of the seller and the outcomes of their interactions become more important [4]. Established customers are familiar with the purchasing process associated with the specific seller and may value streamlined, efficient interactions in which providers address their needs quickly [18]. Because current customers have more experience with the seller, they likely develop different perceptions of the importance or value of additional staff at the booth because firm investments in staffing signal a commitment to streamlined interactions. Thus, we propose:

$\mathrm{H}_{2 \mathrm{~b}}$ : The number of booth personnel has a stronger effect on current customers than on prospective customers.

\subsection{Effects of Post-show Selling Investments}

Firms are interested in closing qualified sales leads. Following a trade show visit, qualified leads typically require additional interactions with sales representatives before the purchase occurs. The post-show interactions allow sellers to answer buyers' questions and reinforce the product benefits without competitive distractions. The significant emphasis on postshow follow-up reflects its direct impact on sales conversion [23]. We propose:

$\mathrm{H}_{3 \mathrm{a}}$ : Post-show selling efforts have a direct, positive effect on sales conversions.

Building on the preceding arguments, we predict that established customers place more emphasis on renewing the relationship with their suppliers through a trade show visit, whereas prospects focus more on broad information gathering [7]. Therefore, post-show follow-up efforts should be more effective for closing sales with established customers because for these buyers, the efforts signal a relationship commitment from the seller. The post-show contact reinforces the buyerseller relationship [7], such that it should effectively facilitate sales conversion. Thus,

$\mathrm{H}_{3 \mathrm{~b}}$ : Post-show selling efforts have a stronger effect on current customers than on prospective customers.

\section{Method}

\subsection{Empirical Setting and Data}

To test our hypotheses, we examined data pertaining to the marketing variables employed before, during, and after a trade show by exhibitors, perceptions of the attendees at that show, and their subsequent purchase behavior. The data reflect several types of shows. From a research design standpoint, we undertake a triadic (attendees, exhibitors, and show organizers) and longitudinal (before and after show) data collection exercise, which avoids issues of single source bias and provides a robust test of our hypotheses. 
Our collaborator was a large, multinational, information technology corporation in the USA (hereafter, exhibiting firm) that specializes in developing and manufacturing computing data storage and networking hardware, designing software, and delivering services. Supplemental services constitute a large portion of its revenue, and the firm exhibits at around 50 different trade shows every year. It hired an independent market research firm to gauge visitor perceptions; this market research firm administered the survey to all attendees who visited the exhibiting firm's booth at specific trade shows. Attendees indicated their role in their employing organization and their prior relationship with the exhibiting firm (as described subsequently). A follow-up survey 120 days after the show inquired whether the attendees purchased any of the exhibiting firm's products that they saw at the show. We obtained attendee-level data (perceptions and intentions at the show and objective purchase data after the show) related to 10 shows where the firm exhibited. Finally, we gathered the detailed characteristics of each trade show from the show organizer.

\subsection{Measures}

\subsubsection{Dependent Variables}

We assessed purchase intentions with a categorical question, asking whether the attendee intended to buy any products viewed at the show from the exhibiting firm (INTENTION). We measured purchase behavior 120 days after the show with a categorical question asking whether the attendee bought any of the exhibiting firm's products viewed at the show (PURCHASE).

\subsubsection{Independent Variables}

We measured the exhibiting firm's pre-show promotional marketing efforts (PRESHOWPROM) as the sum of two dichotomously coded measures, pertaining to whether it used e-mailed or personal invitations to notify potential attendees of its presence at the trade show. The staff per shift count (BOOTHSTAFF) provided a proxy for the atshow marketing effort. All else being equal, more staff per shift should enable the exhibiting firm to reach out to more booth visitors and provide greater personal attention. Finally, we used a single-item, categorical measure of post-show sales contacts by the exhibiting firm (POSTSHOW CONTACT) coded as 1 if the attendee was contacted by the salesperson after the show and 0 otherwise. We controlled for show type (public sector, enterprise firm show, small business show, or consumer products show) with dummy variables.

\subsubsection{Contingency Variable}

We determined whether each attendee was a current customer of the exhibiting firm with a dichotomous measure in the survey (CURRENT_CUSTOMER) equal to 1 if the attendee was a customer and 0 otherwise. We provide the descriptive statistics of all the measures in Table 2.

\subsection{Sample Characteristics}

Our final data set consisted of 2299 data points. The data combined attendee perceptions of the exhibitor booth and purchase information from 10 trade shows that the exhibitor participated in during 2008-2009. We also obtained data about pre-show and at-show marketing efforts from the exhibitor for each of the 10 shows.

\subsection{Model Specification}

We modeled the attendee purchase process as a series of two stages marked by concrete outcomes: (1) purchase intentions after visiting the exhibitor's booth at the trade show and (2) purchase decisions 120 days after the trade show. Both outcomes depend on the exhibiting firm's marketing efforts and also are prone to contingent effects, as noted in the hypotheses (see Fig. 1). In addition, the outcome of stage 2 (PURCHASE) is driven by the outcome of stage 1 (INTENTION). In adopting the model specification and underlying functional forms, which we describe next, we were guided by the need to capture the underlying phenomena in a reasonably parsimonious, robust manner [16, 22].

\subsubsection{Stage 1: Purchase Intention Model}

We modeled the attendee's purchase intention (INTENTION) using a logit specification. Using INTENTION ${ }_{i j}$ to denote the intention to purchase, expressed by attendee $i$ following a booth visit at show $j\left(\right.$ INTENTION $_{i j}=0$ or 1$)$, we can express the probability as:

$$
\begin{aligned}
\ln \left(\frac{P I_{i j}}{1-P I_{i j}}\right) & =\alpha_{0}+\alpha_{1} \text { PRESHOWPROM }_{j} \\
& +\alpha_{2} \text { BOOTHSTAF F }_{j}+\alpha_{3} \text { CURRENTCUSTOMER }_{i j} \\
& +\alpha_{4} \text { PRESHOWPROM }_{j}^{*} \text { CURRENTCUSTOMER } \\
& \\
& +\alpha_{5} \text { BOOTHSTAF F F }_{j}^{*} \text { CURRENTCUSTOMER } \\
& +\boldsymbol{\alpha}_{6} \text { SHOW TYPE }_{j}+\varepsilon_{i j}
\end{aligned}
$$

where $\alpha_{1}$ and $\alpha_{2}$ capture the main effects of pre-show promotions and at-show efforts, respectively, and $\alpha_{3}$ denotes the main effect of customer type. The coefficients $\alpha_{4}$ and $\alpha_{5}$ denote the interaction effect between each marketing effort 
Table 2 Descriptive statistics

\begin{tabular}{|c|c|c|c|c|}
\hline Variable type & Notation & Operationalization & Mean & Std dev. \\
\hline Short-term outcome & INTENTION & $\begin{array}{l}\text { Coded as } 1 \text { if the attendee indicated an intention } \\
\text { to purchase following the show and } 0 \text { if not }\end{array}$ & \multicolumn{2}{|c|}{$43 \%$ indicated intentions } \\
\hline Long-term outcome & PURCHASE & $\begin{array}{l}\text { Coded as } 1 \text { if the attendee bought a product } \\
\text { following the trade show and } 0 \text { if not }\end{array}$ & \multicolumn{2}{|c|}{$13 \%$ purchased } \\
\hline Pre-show marketing & PRESHOWPROM & $\begin{array}{l}\text { Average of two dichotomously coded measures } \\
\text { of promotional effort }\end{array}$ & .45 & .58 \\
\hline At-show marketing & BOOTHSTAFF & Measure of number of staff per shift & 18.13 & 13.78 \\
\hline Post-show marketing & POSTSHOW_CONTACT & $\begin{array}{l}\text { Coded as } 1 \text { if the attendee was contacted by } \\
\text { salesperson after the show and } 0 \text { if not }\end{array}$ & \multicolumn{2}{|c|}{$\begin{array}{l}17 \% \text { of attendees indicated post-show } \\
\text { contact }\end{array}$} \\
\hline Contingency & CURRENT_CUSTOMER & $\begin{array}{l}\text { Coded as } 1 \text { if the attendee has been a customer } \\
\text { of the firm and } 0 \text { if the attendee is a new } \\
\text { customer }\end{array}$ & \multicolumn{2}{|c|}{$\begin{array}{l}70 \% \text { of attendees indicated being a } \\
\text { current customer }\end{array}$} \\
\hline
\end{tabular}

variable (PRESHOWPROM, BOOTHSTAFF) and customer type. Finally, $\alpha_{6}$ denotes the vector of show type dummy

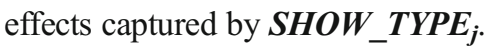

\subsubsection{Stage 2: Attendee Purchase Model}

We modeled the attendee's purchase decision (PURCHASE) using a logit specification. With $P U R C H A S E_{i j}$ as the purchase by attendee $i$ following a booth visit at show $j$, we express the probability of purchase $\mathrm{P}_{\mathrm{ij}}\left(P U R C H A S E_{i j}=1\right)$ as:

$$
\begin{aligned}
& \ln \left(\frac{P_{i j}}{1-P_{i j}}\right)=\beta_{0}+\beta_{1} \text { INTENTION }_{j} \\
& \quad+\beta_{2} \text { POSTSHOWCONTACT }_{j}+\beta_{3} \text { CURRENTCUSTOMER }_{i j} \\
& \quad+\beta_{4} \text { POSTSHOWCONTACT }_{j}{ }^{*} \text { CURRENTCUSTOMER } \\
& \\
& \quad+\boldsymbol{\beta}_{5} \text { SHOWTYPE }_{j}+\vartheta_{i j},
\end{aligned}
$$

where $\beta_{1}, \beta_{2}$, and $\beta_{3}$ are the main effects of purchase intention, post-show contact, and customer type, respectively, $\beta_{4}$ captures the interaction effect between post-show contact and customer type, and $\beta_{5}$ denotes the vector of show type dummy

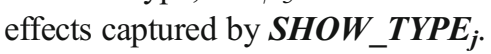

We estimated the two logit models separately, one step at a time. Purchase is observed rather infrequently (i.e., only $13 \%$ of cases). Whereas linear regression models would be unaffected by this rare event occurrence, logit models could sharply underestimate the probability of rare events and provide a biased interpretation of the drivers of the binary outcome of interest [14]. Therefore, we used a bias-corrected estimate and robust standard error, as prescribed by King and Zeng [14] for rare event logit models, to assess the purchase model outcome in the second stage. ${ }^{2}$ The basic intuition beyond this bias correction is to correct for finite sample and rare event biases and standard error inconsistency, as might arise with traditional analyses.

\footnotetext{
${ }^{2}$ We used STATA's ReLogit command to estimate the model in Eq. 2.
}

\section{Results}

We present the estimation results of the purchase intention model (short-term outcome) in Table 3 and the purchase model (long-term outcome) in Table 4. For both models, we present the main effects-only model as well as our final model to illustrate the stability of our coefficient estimates when we add the interaction effect.

\subsection{Purchase Intention Model}

First, the test of $\mathrm{H}_{1}$ a reveals a positive main effect of PRESHOWPROM on purchase intentions, but it is not significant $(b=.04, n s)$. We also do not find support for the interaction effect predicted in $\mathrm{H}_{1 \mathrm{~b}}$ i.e., there is no evidence that PRESHOWPROM has a stronger effect on the purchase intentions of current customers compared with new customers $(b=.04, n s)$. This result could suggest that PRESHOWPROM builds awareness but is unlikely to influence purchase intentions directly.

Second, with regard to the role of BOOTHSTAFF, as we predicted in $\mathrm{H}_{2 \mathrm{a}}$, the main effect on purchase intentions is positive and significant $(b=.01, p<.05)$. However, the negative and significant interaction effect counters the direction anticipated in $\mathrm{H}_{2 \mathrm{~b}}$. Specifically, BOOTHSTAFF has a stronger effect on purchase intentions among new customers than current customers $(b=-.0003, p<.05)$. We posit that booth staff's role as information providers for new customers might be more important than their role in retaining or providing marginal information to existing customers.

\subsection{Attendee Purchase Model}

The estimates for the attendee purchase model, examining the impact of the short-term outcomes on the long-term outcomes, reveal that the main effect of purchase intention on purchase likelihood is significant $(b=.98, p<.05)$. This positive, significant relationship affirms the value of trade shows in 
Table 3 Estimation results (short-term outcome)

\begin{tabular}{|c|c|c|c|c|c|c|}
\hline \multirow[b]{2}{*}{ Effect } & \multicolumn{3}{|c|}{ Main effects only } & \multicolumn{3}{|c|}{ Main and interaction effects } \\
\hline & Estimate & Std. err. & $\operatorname{Pr}>|t|$ & Estimate & Std. err. & $\operatorname{Pr}>|t|$ \\
\hline Intercept & -1.37 & .21 & $<.001$ & -1.30 & .22 & .05 \\
\hline PRESHOWPROM & .30 & .16 & .06 & .04 & .20 & .86 \\
\hline BOOTHSTAFF & .004 & .003 & .18 & .01 & .003 & .002 \\
\hline CURRENT_CUSTOMER & .61 & .10 & $<.001$ & 1.09 & .18 & $<.001$ \\
\hline PRESHOWPROM $\times$ CURRENT_CUSTOMER & & & & .04 & .18 & .82 \\
\hline BOOTHSTAFF $\times$ CURRENT_CUSTOMER & & & & -.0003 & .00008 & $<.001$ \\
\hline ENTERPRISE SHOW & .75 & .21 & $<.001$ & .40 & .23 & .08 \\
\hline CONSUMER-PRODUCT SHOW & .35 & .18 & .054 & .20 & .19 & .28 \\
\hline SMALL BUSINESS SHOW & 1.08 & .24 & $<.001$ & 1.48 & .26 & $<.001$ \\
\hline
\end{tabular}

Italicized estimates are statistically significant at the $95 \%$ confidence level

generating positive intentions that ultimately affect purchases. We also find that the main effect of POSTSHOW CONTACT on purchase likelihood, as we predicted in $\mathrm{H}_{3 \mathrm{a}}$, is positive and significant $(b=3.33, p<.05)$. In support of the predicted interaction effect in $\mathrm{H}_{3 \mathrm{~b}}$, the effect of post-show contacts on purchases is higher among current than new customers $(b=.70$, $p<.05$ ).

Thus, we find support for our hypotheses related to the purchase model. In particular, the significant effect of purchase intentions on eventual purchase suggests that marketing mix variables that affect purchase intentions (short-term outcome) also have an indirect effect on eventual purchases (long-term outcome).

\section{Discussion}

The trade show industry is growing steadily, attracting millions of attendees every year. However, exhibitors have no idea how to confirm the value of their marketing efforts decisively, even while they face considerable pressure to demonstrate accountability for their marketing choices. Academic attempts to help exhibitors typically have focused on either the at-booth experience or post-show selling efforts (cf. [9]). However, examining only a single stage of the decisionmaking process, such as at-show or post-show, provides an incomplete picture of how B2B buyers move through the purchase funnel and the sequence of events that lead them to a purchase decision.

To address such issues, we present a conceptual and empirical analysis of the effects of pre-show, at-show, and postshow marketing efforts on short-term and long-term outcomes that are of interest to firms. We also demonstrate the effect of customer type as a contingency variable. Specifically, the effect of booth personnel on purchase intentions is higher for new customers, whereas the effect of post-show contacts on purchases is higher for current customers. In this sense, customer type has an important and differential role in moderating the impact of the marketing mix variables, before, during, and after the show.

Table 4 Estimation results (long-term outcome)

\begin{tabular}{|c|c|c|c|c|c|c|}
\hline \multirow[b]{2}{*}{ Effect } & \multicolumn{3}{|c|}{ Main effects only } & \multicolumn{3}{|c|}{ Main and interaction effects } \\
\hline & Estimate & Robust std. err. & $\operatorname{Pr}>|z|$ & Estimate & Robust std. err. & $\operatorname{Pr}>|z|$ \\
\hline Intercept & -4.22 & .26 & $<.001$ & -3.86 & .30 & $<.001$ \\
\hline PURCHASE INTENTION & .98 & .18 & $<.001$ & .98 & .18 & $<.001$ \\
\hline POSTSHOW_CONTACT & 3.85 & .18 & $<.001$ & 3.33 & .32 & $<.001$ \\
\hline CURRENT_CUSTOMER & .54 & .20 & .006 & .11 & .29 & .71 \\
\hline POSTSHOW_CONTACT $\times$ CURRENT_CUSTOMER & & & & .70 & .35 & .05 \\
\hline ENTERPRISE SHOW & -.06 & .17 & .72 & -.08 & .18 & .64 \\
\hline CONSUMER-PRODUCT SHOW & -.38 & .28 & .17 & -.40 & .28 & .16 \\
\hline SMALL BUSINESS SHOW & .85 & .30 & .005 & .82 & .30 & $<.001$ \\
\hline
\end{tabular}

Italicized estimates are statistically significant at the $95 \%$ confidence level 
We also uncover an indirect effect of at-show marketing mix efforts on purchases through the purchase intention link. Because purchase intentions drive purchase probability, atshow marketing investments have indirect effects on overall purchases. Buyers do not simply use information from one stage of the buying process to narrow their consideration set in the subsequent stage; rather, they carry forward information from prior stages and integrate it with new insights to make a purchase decision. As a result, models that focus on a single stage of the trade show (e.g., at-show or post-show) will fail to capture the dynamics across evaluations in each stage. Such knowledge is helpful for timing the deployment of these instruments and calculating an optimal allocation of marketing mix budgets for each stage of the buying process. Although we do not know the investments in dollar terms for each stage of the purchase process, managers can use our estimation approach and conceptual framework to arrive at such an allocation. Moreover, they can adjust the allocation mix, depending on their propensity to attract prospective or existing customers.

In conclusion, our model and the related estimation approach provide a richer, better understanding of the impact of trade show marketing activities across various stages of attendees' decision-making process in a B2B setting.

Acknowledgments The authors appreciate the financial support and encouragement from the Marketing Science Institute and the feedback on a previous version of this work. They thank Exhibit Surveys Inc. for their help and cooperation in collecting and accessing the various sources of trade show data used in the study. Finally, they wish to thank the participants at the INFORMS Marketing Science Conference, Cologne and the MSI-ISMS Practice Prize Competition, Washington D.C. for comments during the early phases of this project.

\section{References}

1. Anderson NH (1965) Primacy effects in personality impression formation using generalized order effect paradigm. J Pers Soc Psychol 2(1):1-9

2. Anderson NH (1971) Integration theory and attitude change. Psychol Rev 18(3):171-206

3. Bello DC (1992) Industrial buyer behavior at trade shows: implications for selling effectiveness. J Bus Res 25(1):59-80
4. Dagger T, Sweeney J (2005) Shifts in service quality attributes over the customer-provider relationship. Australian and New Zealand Marketing Academy Conference, Perth

5. Dekimpe MG, Francois P, Gopalakrishna S, Lilien GL, Van den Bulte C (1997) Generalizing about trade show effectiveness: a cross-national comparison. J Mark 61(4):55-64

6. Federbush J (2013) "Beyond ROI and ROO: using measurement to enhance decisions and improve exhibit results," White Paper, Exhibit Surveys Inc., NJ

7. Godar SH, O’Connor PJ (2001) Same time next year - buyer trade show motives. Ind Mark Manag 30:77-86

8. Gopalakrishna S, Lilien GL (1995) A three-stage model of industrial trade show performance. Mark Sci 14(1):22-42

9. Gopalakrishna S, Lilien GL, Williams JD, Sequeira IK (1995) Do trade shows pay off? J Mark 59(July):75-83

10. Gopalakrishna S, Roster C, Sridhar S (2010) An exploratory study of attendee activities at a business trade show. J Bus Ind Mark 25(4): 241-248

11. Gopalakrishna S, Williams JD (1992) Planning and performance assessment of industrial trade shows: an exploratory study. Int J Res Mark 3(August):207-224

12. Kent RJ, Allen CT (1994) Competitive interference effects in consumer memory for advertising: the role of brand familiarity. J Mark 58(3):97-105

13. Kerin RA, Cron WL (1987) Assessing trade show functions and performance: an exploratory study. J Mark 51(3):87-94

14. King G, Zeng L (2001) Logistic regression in rare events data. Polit Anal 9(2):137-163

15. Lee CH, Kim SY (2008) Differential effects of determinants on multi-dimensions of trade show performance: by three stages of pre-show, at-show, and post-show activities. Ind Mark Manag 37(2):784-796

16. Lilien GL, Kotler P, Sridhar Moorthy K (1992) Marketing models. Prentice-Hall, Englewood Cliffs

17. Ling-yee L (2007) Marketing resources and performance of exhibitor firms in trade shows: a contingent resource perspective. Ind Mark Manag 36(2):360-370

18. Mittal V, Katrichis JM (2000) New and loyal customers. Marketing Research (Spring): 26-32

19. Oliva R, Sterman JD (2001) Cutting corners and working overtime: quality erosion in the service industry. Mark Sci 47(7):894-214

20. Prins R, Verhoef PC (2007) Marketing communication drivers of adoption timing of a new e-service among existing customers. J Mark 71(2):169-183

21. Rust RT, Verhoef PC (2005) Optimizing the marketing interventions mix in intermediate-term CRM. Mark Sci 24(3):477-489

22. Smith TM, Gopalakrishna S, Chatterjee R (2006) A three-stage model of integrated marketing communications at the marketing-sales interface. J Mark Res 43(November):564-579

23. Smith TM, Gopalakrishna S, Smith PM (2004) The complementary effect of trade shows on personal selling. Int J Res Mark 21:61-76

24. Stevens RP (2005) Trade shows and event marketing: plan, promote and profit. Thomson/Southwestern, Mason 